\title{
Diurnal variations in human corneal thickness
}

\author{
C L Harper, M E Boulton, D Bennett, B Marcyniuk, J H Jarvis-Evans, A B Tullo, \\ A E Ridgway
}

\begin{abstract}
Aim-To elucidate the diurnal variation in human corneal thickness over a 48 hour period.

Method-Changes in central corneal thickness were monitored in eight healthy subjects (four male, four female) aged between 10 and 63 years using an ultrasonic pachymeter. Measurements were made over a 48 hour period-immediately before sleep, immediately upon waking and at 15, 30, 45 minutes, 1, 1.5, 2, 2.5, 3 hours, and at 2 hour intervals thereafter throughout the remainder of each day.

Results-The mean corneal thickness for the group (SD) was 546 (14) $\mu \mathrm{m}$, with a mean overnight increase of $5.5 \%(2.9 \%)$ (range 1.9-12.6\%) and a maximum diurnal increase of $7.2 \%(2.8 \%)$ (range 2.1 $14.3 \%)$. Individual differences in the extent of diurnal and overnight variation occurred within the group. For three subjects, the first reading taken on waking was not the highest and corneal thickness continued to increase.

Conclusion-These data confirm an increase of corneal thickness during sleep, but also reveal considerable variation during waking hours. Thus, the overnight changes in corneal thickness are not truly representative of diurnal variations in human corneal thickness and, in fact, much greater diurnal variation occurs than the $3.0-4.4 \%$ previously reported. (Br f Ophthalmol 1996;80:1068-1072)
\end{abstract}

Department of Ophthalmology, Oxford Road, Manchester M13 9WH

C L Harper

M E Boulton

J H Jarvis-Evans

School of

Management, UMIST, Manchester M60 1QD

D Bennett

Manchester Royal Eye Hospital, Oxford Road, Manchester M13 9WH B Marcyniuk

A B Tullo

A E Ridgway

Correspondence to: Catherine Harper, $\mathrm{PhD}$, Research and Development Department, Hydron Limited, Hawley Lane, Farnborough, Hampshire, GU14 8EW.

Accepted for publication 13 September 1996

Corneal thickness measurements are indicative of the metabolic status of the cornea, as they provide an index of corneal hydration. ${ }^{1}$ Such measurements give valuable information on the physiological status of the cornea and its changes associated with disease, ${ }^{2-4}$ trauma, ${ }^{56}$ and hypoxia. ${ }^{78}$ The healthy human cornea experiences hypoxia on a daily basis beneath the closed eyelid during sleep. ${ }^{910}$ The reduction in oxygen levels beneath the closed eyelid is thought to induce anaerobic metabolism, which causes an accumulation of lactate within the stroma which is followed by an osmotic influx of water. ${ }^{7}$ Other factors could also influence corneal hydration such as the reduced evaporation from the tear film which occurs during the first 2 hours of waking, ${ }^{11}$ intraocular pressure which increases rapidly after sleep, ${ }^{12}$ and body temperature which changes on a diurnal basis decreasing during night-time sleep and increasing throughout the day. ${ }^{13}$
Upon opening the eyelid at waking the corneal thickness is reputed to return rapidly to normal. Thus, corneal thickness changes on a diurnal basis. Such diurnal variations in corneal thickness have been identified in a variety of species, including rabbit, ${ }^{14}$ cat, ${ }^{15}$ primate, ${ }^{16}$ and human. ${ }^{917-20}$

It still remains unclear whether overnight changes in human corneal thickness are truly representative of the diurnal variation occurring throughout any 24 hour period or whether the pattern of thickness changes is the same on consecutive days. The aim of this study was to use ultrasonic pachymetry to elucidate the diurnal variation in human corneal thickness in a group of normal healthy human subjects over a 48 hour period.

\section{Materials and methods}

\section{SUBJECTS}

Eight subjects (four male, four female) aged between 10 and 63 years participated in the study. All subjects were free from ocular disease, had adequate tear film production (a minimum of $15 \mathrm{~mm}$ in 5 minutes using Schirmer's tear test), and were unadapted to contact lens wear. Individuals were maintained on a normal diet and, because of the effects of alcohol consumption on corneal thickness, ${ }^{21}$ no alcohol was consumed in the 24 hours before the study period. Also, where relevant, no females were menstruating or ovulating at the time of the study as increases in oestrogen levels are accompanied by increased corneal thickness. ${ }^{22}$

It has already been ascertained that different humidity levels have no significant effect on the deswelling function of the human cornea. ${ }^{23}$ For this reason and so as not to interfere with regular sleep patterns, all corneal thickness measurements were made in the person's own home. This research followed the tenets of the declaration of Helsinki (1964). Informed consent was obtained after the nature and possible consequences of the study were explained.

PROCEDURE TO MEASURE CORNEAL THICKNESS A Humphrey-Allergan ultrasonic pachymeter (model 850 ) with a handheld transducer was used to measure central corneal thickness readings. The ultrasonic pachymeter calculates readings based on an ultrasonic velocity of $1640 \mathrm{~m} / \mathrm{s}$ for normal human corneal thickness at $34.5^{\circ} \mathrm{C}$, which is the temperature at the corneal surface in vivo. 
Table 1 Repeated measures analysis of variance was performed on the raw data with sex as the between subject factor and day and time of day as the within subject factors

\begin{tabular}{|c|c|c|c|c|c|}
\hline Source & ss & $d f$ & $m s$ & $f$ & p Value \\
\hline $\begin{array}{l}\text { Between subjects: } \\
\text { Sex } \\
\text { Residual }\end{array}$ & $\begin{array}{r}2313.01 \\
345463.02\end{array}$ & $\begin{array}{l}1 \\
5\end{array}$ & $\begin{array}{r}2313.01 \\
69092.60\end{array}$ & 0.03 & 0.8620 \\
\hline $\begin{array}{l}\text { Within subjects: } \\
\text { Day } \\
\text { Day.sex } \\
\text { Residual }\end{array}$ & $\begin{array}{r}700.42 \\
38.40 \\
2056.05\end{array}$ & $\begin{array}{l}1 \\
1 \\
6\end{array}$ & $\begin{array}{r}700.42 \\
38.40 \\
342.67\end{array}$ & $\begin{array}{l}2.04 \\
1.03\end{array}$ & $\begin{array}{l}0.2027 \\
0.7492\end{array}$ \\
\hline $\begin{array}{l}\text { Time } \\
\text { Time.sex } \\
\text { Residual }\end{array}$ & $\begin{array}{r}16244.56 \\
850.36 \\
9995.28\end{array}$ & $\begin{array}{l}14 \\
14 \\
84\end{array}$ & $\begin{array}{r}16244.56 \\
60.74 \\
118.99\end{array}$ & $\begin{array}{l}9.75 \\
0.51\end{array}$ & $\begin{array}{l}<0.0001 \\
0.9209\end{array}$ \\
\hline $\begin{array}{l}\text { Day.time } \\
\text { Day.time of day } \\
\text { Residual }\end{array}$ & $\begin{array}{r}336.71 \\
895.48 \\
4442.95\end{array}$ & $\begin{array}{l}14 \\
14 \\
84\end{array}$ & $\begin{array}{l}26.19 \\
63.96 \\
52.89\end{array}$ & $\begin{array}{l}0.50 \\
1.21\end{array}$ & $\begin{array}{l}0.9297 \\
0.2843\end{array}$ \\
\hline
\end{tabular}

Filliben correlation coefficient $=0.9912$.

ss $=$ sums of squares, $\mathrm{df}=$ degrees of freedom, $\mathrm{ms}=$ mean square, $\mathrm{f}=F$ statistic.

\section{ACCURACY}

A Humphrey-Allergan test block of known thickness (560 (SD 11) $\mu \mathrm{m}$ at $25^{\circ} \mathrm{C}$ ) was used to monitor the accuracy of the pachymeter. The test block was measured in the calibration mode setting, which adjusts the ultrasonic frequency to measure Perspex at $25^{\circ} \mathrm{C}$. Holding the pachymeter probe tip on the test block and moving the body of the probe away from the perpendicular while keeping the tip positioned in the same place produced a maximum variation of plus or minus $0.8 \%$ of the mean test block thickness reading. Beyond a slight deviation from the perpendicular angle on both the test block and the cornea, thickness readings would not register because the probe tip was incorrectly aligned. Fifteen test block readings have been taken twice a week over a 3 year period.

\section{REPRODUCIBILITY}

The same operator was used in all studies. The operator has performed ultrasonic pachymeter on a weekly basis for a period of 3 years. The reproducibility of the operator was assessed by taking central corneal thickness readings every 10 minutes over a 1 hour period for three male subjects (aged 24, 28, and 29 years). The first reading was taken at 14.00 hours as corneal thickness was considered to be more stable at this time of day. Males were chosen to eliminate any effect of the menstrual cycle on corneal thickness. ${ }^{22}$

\section{CALCUlations}

Percentage overnight changes in corneal thickness were calculated using the difference between presleep and postsleep corneal thickness:

$\%$ Overnight change in corneal thickness = ((postsleep thickness presleep thickness)/presleep thickness) $\times 100$

The percentage maximum diurnal thickness change occurring during any 24 hour period was calculated using the difference between the maximum and minimum corneal thickness readings measured on each day (for the purpose of this study 'a day' is defined as the period between presleep reading and the penultimate reading on the following day).
$\%$ Diurnal variation $=$

((highest reading of day - lowest reading of day)/ lowest reading of day) $\times 100$

PROTOCOL

The ultrasonic pachymeter was used to take three central corneal thickness readings of the right eye of each individual during the hour before night-time sleep. Initially, 10 readings were taken, but patients and volunteers objected to this and three readings were found to be a suitable compromise without affecting reproducibility. To locate the centre of the cornea each subject was instructed to gaze directly at an ophthalmic pen light positioned at eye level approximately 2 metres from the subject. Individuals were allowed to wake naturally, but did not sleep at any other time during the day. Immediately on waking, each subject taped down their left eyelid to eliminate the effect of tear film evaporation on corneal deswelling. ${ }^{10}$ Three thickness readings were taken immediately and repeated at the following intervals thereafter: 15, 30, 45 minutes and 1.0, 1.5, 2.0, $2.5,3.0$ hours, and then every 2 hours up to a period of 24 hours.

\section{STATISTICAL ANALYSES}

Repeated measures analysis of variance was performed on the raw data with sex as the between subject factor, and day and time of day as the within subject factors. The analysis was performed using the statistical package GLIM 3.77..$^{25}$ The aim was to determine whether there were significant changes in corneal thickness over the time intervals measured.

Interaction terms between time of day and sex, and day and sex were evaluated to see if there were any differences in male and female corneal thickness at any particular time of day or on any particular day. The results of the analysis were converted into the standard analysis of variance table (Table 1 ). The goodness of fit of the model, and the validity of the distributional assumptions made, were tested by constructing a half normal plot from the model residuals and computing the Filliben correlation coefficient. ${ }^{26}$ Values of this coefficient in excess of 0.95 were taken as indicating an acceptable fit to the data. Significant differences between baseline and the remaining time points were found using Tukey's critical range test. ${ }^{27}$

\section{Results}

\section{ACCURACY}

Thickness readings were consistently within the manufacturer's test block range of 560 (SD 11) $\mu \mathrm{m}$ at $25^{\circ} \mathrm{C}$ during the 3 years of using the ultrasonic pachymeter.

\section{REPRODUCIBILITY}

For any 10 readings taken at any time point (Fig 1), a typical value for the standard error of the mean (SEM) was plus or minus $2 \mu \mathrm{m}$. The SEM over the 1 hour period for each individual was plus or minus $1 \mu \mathrm{m}$. 


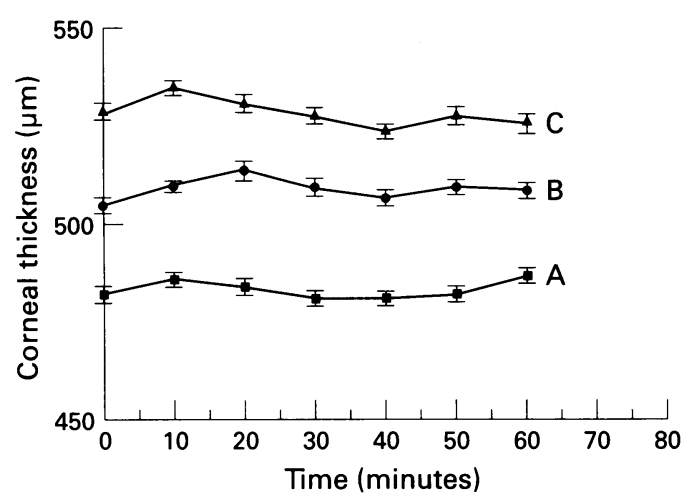

Figure 1 To assess the reproducibility of the operator 10 central corneal thickness readings were taken every 10 minutes for 1 hour (starting at $2 \mathrm{pm}$ ) for three males aged (A) $24,(B) 28$, and (C) 29 years old. Vertical bars $=S D$.
DIURNAL VARIATION IN HUMAN CORNEAL

THICKNESS

Corneal thickness increased overnight (Fig 2) and decreased after waking. However, corneal thickness did not remain constant throughout the day. Differences in the magnitude and pattern of swelling were seen between day 1 and day 2 of the study and also between individuals. For three subjects, the first reading taken on waking was not the highest and corneal thickness continued to increase.

Mean overnight variation in central corneal thickness was $5.2 \%(2.9 \%)$ for the group and mean diurnal variation was $7.2 \%(2.8 \%)$ for the group (Table 2). For all but one subject (day 1 for the 10-year-old female), the degree of diurnal variation was greater than the overnight increase in corneal thickness.
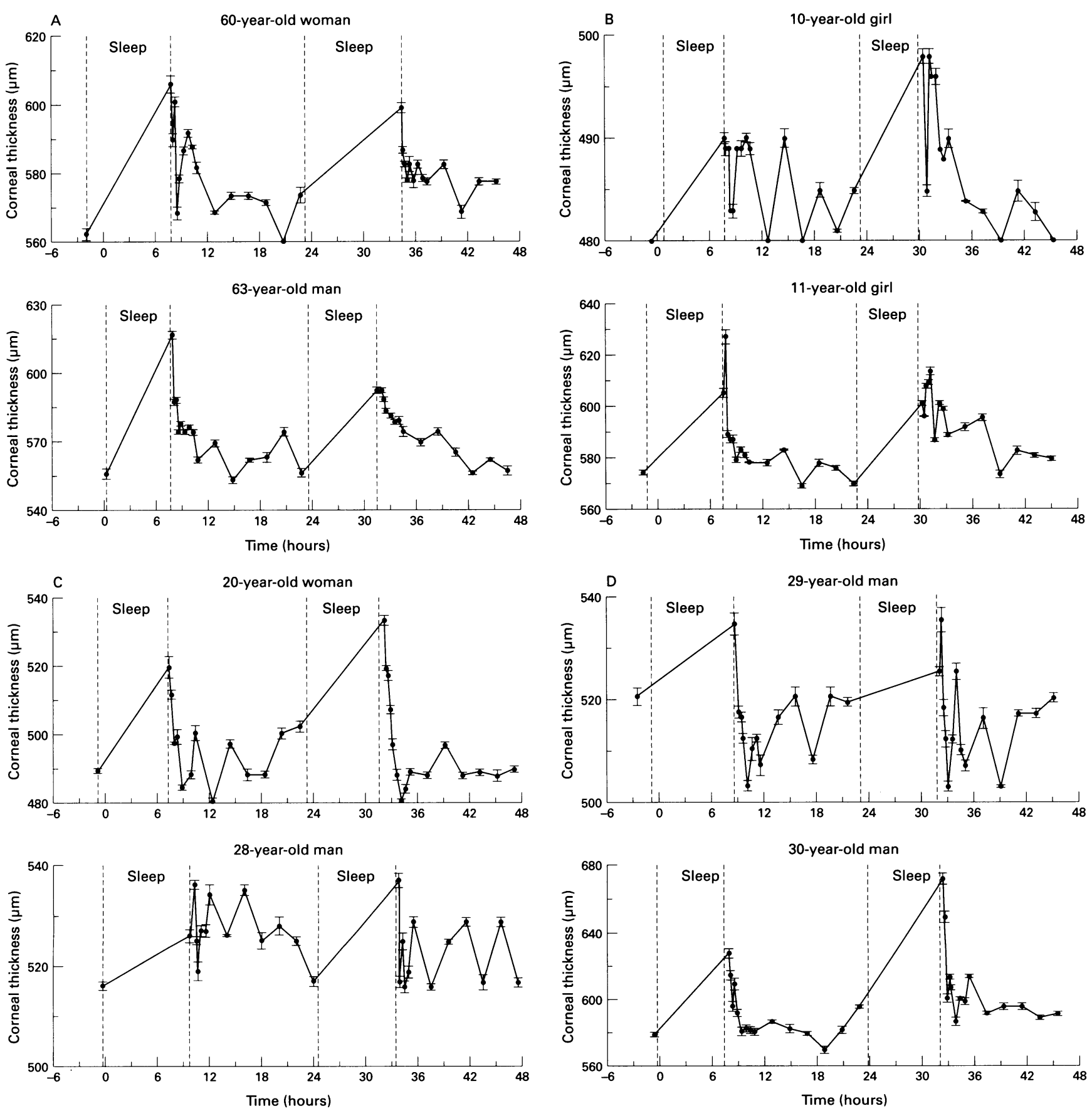

Figure 2 Diurnal variation in central corneal thickness of eight subjects ranging from 10 to 63 years of age. Measurements were taken at different time intervals over a 48 hour period. Vertical bars $=S D$. 
Table 2 Diurnal variations in human corneal thickness

\begin{tabular}{lllllllllll}
\hline Subject & $A$ & $B$ & $C$ & $D$ & $E$ & $F$ & $G$ & $H$ & $M e a n$ & $(S D)$ \\
\hline $\begin{array}{l}\text { Age (years) } \\
\text { Sex }\end{array}$ & 10 & 11 & 28 & 28 & 29 & 30 & 60 & 63 & & \\
$\begin{array}{l}\text { Day 1 } \\
\text { \% overnight }\end{array}$ & $\mathrm{F}$ & $\mathrm{F}$ & $\mathrm{M}$ & $\mathrm{F}$ & $\mathrm{M}$ & $\mathrm{M}$ & $\mathrm{F}$ & $\mathrm{M}$ & & \\
$\begin{array}{l}\text { Day 1 } \\
\text { \% maximum diurnal variation }\end{array}$ & 2.1 & 5.4 & 1.9 & 6.1 & 2.7 & 8.3 & 7.6 & 11.6 & 5.7 & $(3.1)$ \\
$\begin{array}{l}\text { Day 2 } \\
\text { \% overnight }\end{array}$ & 2.1 & 6.3 & 3.9 & 8.1 & 6.2 & 10.0 & 8.2 & 11.8 & 7.1 & $(2.9)$ \\
$\begin{array}{l}\text { Day 2 } \\
\text { \% maximum diurnal variation }\end{array}$ & 2.7 & 5.4 & 4.1 & 5.4 & 1.2 & 12.6 & 4.4 & 6.5 & 5.3 & $(3.2)$ \\
$\begin{array}{l}\text { Mean } \\
\text { \% overnight }\end{array}$ & 3.8 & 7.0 & 4.3 & 11.1 & 6.4 & 14.3 & 5.4 & 6.5 & 7.4 & $(3.4)$ \\
$\begin{array}{l}\text { Mean } \\
\text { \% maximum diurnal variation }\end{array}$ & 2.4 & 5.4 & 3.0 & 5.8 & 2.0 & 10.5 & 6.0 & 8.9 & 5.5 & $(2.9)$ \\
\hline
\end{tabular}

Individual changes in overnight and diurnal thickness varied greatly within the group, with a range of $1.9-12.6 \%$ (overnight increase) and 2.1-14.3\% (maximum diurnal variation) during any day. There were five individuals whose overnight increase in corneal thickness in either day was greater than 3-4\%; two of these subjects (30-year-old male and 63-year-old male) showed overnight increases of at least $10 \%$ during one or both days of the study. Three individuals showed a maximum diurnal variation of $10 \%$ or more (28-year-old female, 30 and 63-year-old males). The magnitude of the variation differed on consecutive days for each individual.

STATISTICAL ANALYSES

The results of the statistical analyses (Table 1) indicate that there are no overall sex differences in corneal thickness $(p=0.8620)$. There were also no significant effects of time of day of measurement $(p=0.2027)$, day by sex interaction $(p=0.7492)$, time of day by sex interaction $(p=0.9209)$, or day of measurement by sex interaction $(p=0.2843)$. These results indicate that corneal thickness behaves similarly for both days irrespective of sex. There was, however, a highly significant time of day effect $(\mathrm{p}<0.0001)$.

\section{Discussion}

Corneal thickness was found to increase overnight, which is in agreement with previous studies. $^{917-20}$ However, we report a level of overnight variation in central human corneal thickness of $5.5 \%$ for the group which is higher than the values (3-4.4\%) previously reported. In fact, the mean diurnal variation in central corneal thickness was $7.2 \%$ for the group. For each volunteer, maximum variation during any day was greater than the overnight increase in corneal thickness, except for the 10-year-old female. On day 1 the overnight thickness increase was the same as her maximum diurnal variation; however, she later admitted to waking up at 4.30 am on day 1 , but felt that this was too early to wake the operator. Our results suggest that overnight changes in corneal thickness are not truly representative of actual diurnal variation. While we can compare our overnight changes in corneal thickness with other studies, it is difficult to compare diurnal studies as most authors do not report the full 24 hour cycle. ${ }^{18}$
The results of this study are in agreement with Gerstman's study ${ }^{18}$ who reported an average increase of $7.8 \%$ which is similar to our mean maximum diurnal variation of $7.2 \%$. However, in Gerstman's study no presleep reading was taken (the lowest value occurring throughout the study was used as the baseline) and no thickness measurement was made immediately on waking; this also occurs in two other optical pachymetry studies. ${ }^{1719}$ Mertz used electronic digital pachymetry and reported overnight swelling of $4.33 \%$ in nine subjects (three male, six female) ${ }^{20}$ The highest overnight thickness increase in Mertz's study was $9.7 \%$, which is similar to the highest readings of our study.

The most recent published study ${ }^{10}$ involved electronic digital pachymetry and reported a $3 \%$ overnight increase in corneal thickness. This study was limited to a group of youths of about 19 years of age. Our study includes the widest age range reported so far in a diurnal study of this nature (10 to 63 years). To date this study is the first (a) to use an ultrasonic pachymeter to monitor diurnal variations in human corneal thickness,(b) to follow human corneal thickness over 2 full days, and (c) to report the diurnal variation of corneal thickness of a child.

Local anaesthetic was not used in this study for several reasons. Firstly, a drop of local anaesthetic can induce lacrimation, which is undesirable in view of the linear relation between corneal thickness and hydration. ${ }^{1}$ Also local anaesthetic eyedrops are toxic to the corneal epithelium. Continuous instillation of these drops throughout the day could disrupt the epithelium and affect its role as a structural barrier to the influx of fluid from the tear film. ${ }^{28}{ }^{29}$ In addition to its properties as a barrier, the active movement of ions by the epithelium ${ }^{30}$ augments the activity of the endothelium in maintaining corneal dehydration. $^{31}{ }^{32}$ Therefore the damage to the epithelium caused by local anaesthetic might influence corneal thickness by disrupting the physical barrier of the epithelium and also affecting ion transport. In studies of this nature, it is important that the subject feels at ease and relaxed about the techniques being performed. Repeated use of drops at regular intervals throughout the day would cause discomfort to the volunteers who in fact preferred the readings to be performed without local anaesthetic. 
Ultrasonic pachymetry does require the probe tip to touch the epithelial surface which might cause some degree of epithelial disruption. Other methods of pachymetry include optical and electronic digital pachymetry. For a study of this nature, the major advantage of optical pachymetry over both ultrasonic and electronic digital pachymetry is that the optical pachymeter is a non-contact method. The major limitation of the optical pachymeter (which requires a slit-lamp) is comparative size. Therefore, for diurnal studies it was not practical to transport an optical pachymeter to the homes of the subjects, where the investigations took place.

Mertz investigated the accuracy of the technique and reported a standard deviation of $5 \mu \mathrm{m}$ for 10 readings. ${ }^{20}$ As can be seen in Figure 1 , the study of the reproducibility of the operator gave a standard deviation value of plus or minus $3 \mu \mathrm{m}$ which provides a similar level of accuracy. Other reports have not commented an the accuracy of the pachymetry technique.

In summary, mean overnight swelling was $5.5 \%$ with a maximum mean diurnal variation of $7.2 \%$ and considerable variability was seen between individuals. Corneal thickness is highly variable during any 24 hour period and does not follow the regular pattern of overnight swelling and exponential decay previously reported.

The authors would like to thank all volunteers for their help and cooperation. This study was supported by the Kershaw Trust and the North Western Regional Health Authority.

1 Hedbys BO, Mishima S. The thickness-hydration relationship of the cornea. Exp Eye Res 1966;5:221-8.

2 Mandell RB, Polse KA, Brand RJ, Vastine D, Demartini D, Flom $R$. Corneal hydration in Fuchs' dystrophy. Invest Ophthalmol Vis Sci 1989;30:845-52.

3 Insler MS, Baumann JD. Corneal thinning syndromes. Ann Ophthalmol 1986;18:74-5.

4 Weston BC, Bourne WM, Polse KA, Hodge DO. Corneal hydration in diabetes mellitus. Invest Ophthalmol Vis $S c i$ 1995;36:586-95.

5 Huff JW. Contact lens-induced edema in vitro. Pharmacology and metabolic considerations. Invest Ophthalmol Vis Sci 1991;32:346-53.

6 Cheng H, Bates AK, Wood L, McPherson K. Positive correlation of corneal thickness and endothelial cell loss. Serial measurements after cataract surgery. Arch Ophthalmol 1988;106:920-2.
7 Klyce SD. Stromal lactate accumulation can account for corneal oedema osmotically following epithelial hypoxia in the rabbit. F Physiol 1981;312:49-64.

8 Johnson MH, Roger L, Bolz RL, Godio LB. Deswelling of the cornea after hypoxia. Am F Optom Physiol Opt 1985;62 768-73.

9 Efron N, Carney LG. Oxygen levels beneath the closed eyelid. Invest Ophthalmol Vis Sci 1979;18:93-5.

10 Holden BA, Mertz GW, McNally JJ. Corneal swelling response to contact lenses worn under extended wear conresponse to contact lenses worn under extended w
ditions. Invest Ophthalmol Vis Sci 1983;24:218-26.

11 Tomlinson A, Cedarstaff TH. Diurnal variation in tear-film evaporation. $\mathcal{F}$ Br Contact Lens Assoc 1992;13:77-9.

12 Frampton P, Da Rin D, Brown B. Diurnal variation of intraocular pressure and the overriding effects of sleep. $\mathrm{Am}$ f Optom Physiol Opt 1987;1:54-61.

13 Wright $S$. Muscle and the nervous system. In: Keele CA Neil E, Joels N, eds. Samson Wright's applied physiology. Oxford: Oxford University Press, 1992:248-370.

14 Kikkawa Y. Diurnal variations in corneal thickness. Exp Eye Res 1973;15:1-9.

15 Chan-Ling T, Efron N, Holden BA. Diurnal variation of corneal thickness in the cat. Invest Ophthalmol Vis Sci 1985, 26:102-5.

16 Madigan MC, Gillard-Crewther S, Kiely PM, Crewther DP, Brennan NA, Efron N, et al. Corneal thickness changes following sleep and overnight contact lens wear in the primate (Macaca fascicularis). Curr Eye Res 1987;6:809-15.

17 Mandell RB, Fatt I. Thinning of the human cornea on awakening. Nature 1965;208:292-3.

18 Gerstman DR. The biomicroscope and Vickers image splitting eyepiece applied to the diurnal variation in human ting eyepiece applied to the diurnal variation in

19 Kiely PM, Carney LG, Smith G. Diurnal variations of corneal topography and thickness. Am $\mathcal{f}$ Optom Physiol Opt 1982.59.976-82.

20 Mertz GW. Overnight swelling of the living human cornea f Am Optom Assoc 1980;51:211-3.

21 Shiono T, Asano Y, Hashimoto T, Mizunok K. Temporary corneal oedema after acute intake of alcohol. $\mathrm{Br} \mathcal{F}$ Ophthalmol 1987;71:462-5.

22 Kiely PM, Carney LG, Smith G. Menstrual cycle variations of corneal topography and thickness. Am $\mathcal{F}$ Optom Physio Opt 1983;60:822-9.

23 Bourasssa S, Benjamin WJ, Boltz RL. Effect of humidity on the deswelling function of the human cornea. Curr Eye Res the deswelling functi

24 Aitken M, Anderson D, Francis B, Hinde J. Statistical modelling in GLIM. Oxford: Clarendon Press, 1989.

25 Baker RJ. GLIM 3.77 reference manual. Oxford: Numerica Algorithms Group, 1985.

26 Filliben J. The probability plot correlation coefficient test for normality. F Technometrics 1975;17:111-7.

27 Tukey JW. Exploratory data analysis. Reading, UK: AddisonWesley, 1977.

28 Maurice DM. The permeability to sodium ions in the living rabbits cornea. $\mathcal{F}$ Physiol 1951;112:367-91.

29 Mishima S, Hebdys BO. The permeability of the cornea epithelium and endothelium. Exp Eye Res 1967;6:10-28

30 Klyce SD, Crosson CE. Transport processes across the rabbit corneal epithelium. A review. Curr Eye Res 1985;4:323 31.

31 Klyce SD, Bonanno JA. Role of the epithelium in corneal hydration. In: Cavanagh HD, ed. The cornea: transactions of the world congress on the cornea III. New York: Raven Press, 1988:159-64.

32 Candia OA. Forskolin-induced $\mathrm{HCO}_{3}^{-}$current across the apical membrane of the frog corneal epithelium. $A m \mathcal{F}$ Physiol 1990;259: 215-23. 